\title{
Perceptions of blindness related to smoking: a hospital- based cross-sectional study
}

G Bidwell ${ }^{1}$, A Sahu ${ }^{1,4}$, R Edwards², RA Harrison ${ }^{3}$, J Thornton ${ }^{2}$ and SP Kelly ${ }^{1}$

\begin{abstract}
Aims Smoking is associated with several serious eye diseases. Awareness of smoking and blindness, and its potential to act, as a stimulus to assist stopping smoking has not been investigated.

Methods A cross-sectional survey using a structured interview of adult patients attending district general hospital ophthalmology, general surgery, and orthopaedic clinics. The interview investigated the awareness and fear of blindness for three established smokingrelated diseases, and a distractor condition (deafness), and the likelihood that smokers would quit on developing early signs of each condition.
\end{abstract}

Results Response was $89.1 \%$ (358/402). In all, $183(51.1 \%)$ of responders were male and $175(48.9 \%)$ female. Only $9.5 \%$ of patients believed that smoking was definitely or probably a cause of blindness, compared with $\mathbf{9 2 . 2 \%}$ for lung cancer, $\mathbf{8 7 . 6 \%}$ for heart disease, and $70.6 \%$ for stroke. Patients ranked their fear of each of the five conditions, scoring five for the most feared and one for the least feared. Patients were significantly $(P<0.01)$ less fearful of blindness (mean score 2.80 ) than lung cancer (3.89), heart disease (3.58), and stroke (3.35). About one-half of smokers stated that they would definitely or probably quit smoking if they developed early signs of blindness or the three established smokingrelated conditions, with no significant differences in proportions for these four conditions.

Conclusion The findings suggest that awareness of the risk of blindness from smoking is low, but that the fear of blindness is as compelling a motivation to quit as fear of lung cancer, heart disease, and stroke. The link between smoking and eye disease should be publicised to help reduce smoking prevalence.

Eye (2005) 19, 945-948. doi:10.1038/sj.eye.6701955

Keywords: awareness; blindness; fear; smoking; smoking cessation; health promotion

\section{Introduction}

The association between smoking and eye diseases is well established, especially for agerelated macular degeneration (AMD), though also for thyroid eye disease and cataract among others. ${ }^{1}$ AMD is the principal cause of blindness in developed countries. It is the commonest cause for blind registration in the UK, where there are approximately 214000 (95\% confidence interval (CI): 151 000-310000) individuals with impaired vision secondary to $\mathrm{AMD}^{2}$ and an estimated 54000 people with visual impairment and almost 18000 with blindness caused by AMD related to smoking. ${ }^{3}$

There is minimal understanding of the public's awareness about smoking as a risk factor for blindness. While certain diseases, such as lung cancer and heart disease, receive a high profile in health-promotional campaigns as illnesses caused by smoking, this is not the case for smoking-related eye diseases. It is known that if smokers believe their health will improve as a result of stopping smoking, they have an increased chance of quitting. ${ }^{4}$ We have not identified any studies examining the level of awareness of the link between smoking and eye diseases and the possible impact such awareness would have on smoking behaviour. Preliminary findings from New Zealand ${ }^{5}$ on the impact of television advertisement campaigns on calls to a national Quitline service suggest that information about the link between
${ }^{1}$ Bolton Eye Unit, Bolton Hospitals NHS Trust, Bolton, UK

²Evidence for Population Health Unit, University of Manchester, Manchester, UK

${ }^{3}$ Bolton Primary Care Trust, Bolton, UK

${ }^{4}$ Bury Primary Care Trust, Bury, UK

Correspondence: SP Kelly, Ophthalmology, Bolton Hospitals NHS Trust, Royal Bolton Hospital, Farnworth, Bolton BL4 OJR, UK Tel: + 441204 390694; Fax: + 441204390554 E-mail: Simon.Kelly@ boltonh-tr.nwest.nhs.uk

Received: 19 December 2004

Accepted in revised form: 17 March 2005

Competing Interest: RE is an unpaid chairman of North West Action on Smoking and Health, a campaigning charity 
smoking and blindness may be a potent stimulus for smokers to try and quit.

We performed a cross-sectional study to explore the level of knowledge of the link between smoking and eye disease and the likely impact of that knowledge among UK patients attending ophthalmic and other outpatient departments. Our hypothesis was that few patients would be aware of the risk of eye disease by smoking, but that awareness of the risks to eyesight from smoking would be a strong stimulus for smokers to quit.

\section{Methods}

\section{Subjects and setting}

Adults attending ophthalmology, orthopaedics, and general surgery clinics at a UK District General Hospital between May and June 2004 were invited to participate. We excluded persons aged less than 18 years, or who were unable to give written informed consent or complete the interview. The survey was restricted to individuals with competent English language. The hospital serves a local population of approximately 261000 residents, of whom $49 \%$ are male and $51 \%$ are female, $11 \%$ are non-white (mainly of South Asian origin), and $20 \%$ are aged over 60 . Bolton has many areas of high social deprivation, as indicated by a variety of deprivation indices. ${ }^{6,7}$ Approximated social groups for the local census indicated that $80 \%$ of the local population are from low socioeconomic groups.

\section{Data collection}

Data were collected through a structured interview in the three clinic waiting areas, which included demographic details (age, sex, ethnicity, and job title) and smoking status. Socioeconomic status was assigned from job title using the Registrar General's Occupational Social Class classification, and we then divided participants into high and low socioeconomic status.

Subjects were asked about their awareness of a link between smoking and four smoking-attributable conditions (lung cancer, heart disease, stroke, and blindness) and a 'distractor' condition (deafness). The latter condition (for which we are unaware of evidence of a link with smoking) was included for comparison purposes, and to reduce the risk of over-reporting for the questions relating to blindness because of subjects guessing the focus of the study. Fear of developing each of the five conditions was assessed by asking subjects to rank the five conditions from most to least feared.

Responses were scored from a score of 5 (most feared) to 1 (least feared). For each condition, smokers were asked the likelihood that they would quit smoking if they developed early signs of the condition.

\section{Statistical analysis}

Data from the orthopaedic and general surgery patients were combined for the analysis. Statistical analysis was carried out using SPSS version 10.1 (SPSS Inc., Chicago, IL, USA) or Confidence Interval Analysis (CIA) software. ${ }^{8}$ Differences in means and medians were calculated using the CIA software. The Wilcoxon signed rank and Mann-Whitney tests were used to compare fear rankings for paired and independent sample data, respectively. CIs for differences in proportions were calculated using CIA software, using Wilson's method for paired data and Newcombe's method for nonpaired data.

Approval for this study was granted by the Bolton Local Research Ethics Committee.

\section{Results}

\section{Response and demographic profile of patients}

The researcher approached 402 patients attending the outpatient clinics, of whom $358(89.1 \%)$ agreed to participate. Demographic details of the clinic attenders are given in Table 1 .

The age of participants ranged from 18 to 93 years. The mean age was 59.3 years and was higher among the eye

Table 1 Demographic characteristics of clinic subjects*

\begin{tabular}{|c|c|c|c|}
\hline & $\begin{array}{c}\text { Ophthalmology } \\
\text { outpatient } \\
\text { attenders } \\
(\mathrm{n}=161)\end{array}$ & $\begin{array}{c}\text { Other } \\
\text { outpatient } \\
\text { attenders } \\
(\mathrm{n}=197)\end{array}$ & $\begin{array}{c}\text { All subjects } \\
(\mathrm{n}=358)\end{array}$ \\
\hline Mean age (SD) & $66.8(18.1)$ & $52.9(17.4)$ & $59.1(19.0)$ \\
\hline \multicolumn{4}{|l|}{ Sex: $n(\%)$} \\
\hline Male & 79 (49.1) & $104(52.8)$ & $183(51.1)$ \\
\hline Female & 82 (50.9) & $93(47.2)$ & 175 (48.9) \\
\hline \multicolumn{4}{|l|}{ Ethnicity: $n(\%)$} \\
\hline White & $150(93.8)$ & 185 (95.9) & 335 (94.6) \\
\hline Non-white & $10(6.3)$ & $8(4.1)$ & $18(5.4)$ \\
\hline \multicolumn{4}{|l|}{$\begin{array}{l}\text { Socioeconomic } \\
\text { status: } n(\%)\end{array}$} \\
\hline $\mathrm{High}^{\mathrm{a}}$ & $43(29.7)$ & $72(41.1)$ & 115 (35.9) \\
\hline Low $^{\mathrm{b}}$ & $102(70.3)$ & $103(58.9)$ & $205(64.1)$ \\
\hline
\end{tabular}

*Subjects with missing data have been excluded from the figures in the table.

Socioeconomic status was assigned from job title using the Registrar General's Occupational Social Class classification, and we then divided participants into high and low socioeconomic status: ${ }^{a} \mathrm{High}$ social classes I-II; blow social classes III-V. 
clinic attenders. The numbers of men and women were approximately equal. The population was predominantly (95\%) white. There were no statistically significant differences in sex and ethnicity between eye and other clinic attenders. A significantly higher proportion of eye clinic attenders than attenders at other clinics were from occupational social classes III-V (difference 11\% (95\% CI: $1-22 \%)$ ).

\section{Awareness of the link between smoking and blindness}

The proportion of clinic attenders who believed smoking 'definitely' or 'probably' caused stroke, heart disease, and lung cancer was high-over $70 \%$ for stroke, over $85 \%$ for heart disease, and over $90 \%$ for lung cancer (Table 2). However, only $12 \%$ of eye clinic patients and $7 \%$ of other clinic attenders believed smoking caused blindness, with a similar proportion responding positively to the 'distractor' condition-deafness.

There was a highly statistically significant difference for each comparison between the proportions believing that heart disease, stroke, or lung cancer was caused by smoking and the proportion believing that blindness could be caused by smoking. The proportion of smokers $(5 \%)$ believing that smoking caused blindness was lower than for nonsmokers (11\%), though the difference $6 \%$ (95\% CI: -2 to $11 \%$ ) was not significant.

\section{Fear of blindness and other conditions}

The median (mean) fear ranking score was 4 (3.9) for lung cancer, 4 (3.6) for heart disease, 3 (3.4) for stroke, 2 (2.8) for blindness, and 1 (1.4) for deafness. The differences in rankings between each of the four other conditions and the ranking for blindness were all statistically significantly different $(P<0.001$, Wilcoxon signed rank test). The median (mean) score for fear of blindness was 3 (3.1) among eye clinic attenders and 2 (2.6) among other clinic attenders, with a significant difference in rankings (Mann-Whitney test, $P=0.01$ ). The median (mean) score for fear of blindness was 2 (2.9) among nonsmokers and 2 (2.5) among other clinic

Table 2 Proportion (\%) of clinic subjects believing that smoking definitely or probably caused conditions

\begin{tabular}{lcc}
\hline & $\begin{array}{c}\text { Eye clinic attenders } \\
(\mathrm{n}=157)\end{array}$ & $\begin{array}{c}\text { Other clinic attenders } \\
(\mathrm{n}=192)\end{array}$ \\
\hline Lung cancer & 93 & 92 \\
Heart disease & 85 & 90 \\
Stroke & 70 & 71 \\
Blindness & 12 & 7 \\
Deafness & 6 & 2 \\
\hline
\end{tabular}

attenders, with a significant difference in rankings (Mann-Whitney test, $P=0.02$ ).

\section{Stimulus to quit with early signs of disease}

The difference in proportions stating that they would quit with early signs of blindness compared with early signs of lung cancer was $4 \%$ (95\% CI: -2 to $9 \%$ ), and for early signs of stroke or heart disease compared with early signs of blindness was $2 \%$ (95\% CI: -3 to $6 \%$ ). These differences were not statistically significant.

\section{Discussion}

This is the first study to have examined the awareness and likely impact of the link between smoking and blindness. Strengths of this project included a large sample size and an excellent response rate. We found that few patients, both smokers and nonsmokers, were aware that smoking could cause blindness. This contrasted with high levels of awareness that smoking causes lung cancer and cardiovascular disease. The perceived risk of blindness from smoking, however, was only slightly greater than that for the distractor variable condition, deafness. Although patients were slightly less fearful of blindness from smoking than developing lung cancer or cardiovascular diseases, there was no significant difference in the proportion of smokers who stated that they would quit smoking on developing early signs of eye disease, compared with developing early signs of the three other established smoking-related conditions. We acknowledge that hospital clinic samples may not be representative of the local population (though in practice this is difficult to determine in a hospital sample), and therefore the knowledge and attitudes reported may not be representative of those among the general public.

The findings suggest that increasing the awareness of the link between smoking and blindness may be an effective additional approach to encouraging smoking cessation. The low level of awareness of the link between smoking and blindness, even among eye clinic patients, may reflect both a lack of general public and patient information on the matter and further lack of effective advice about smoking at ophthalmic clinics.

Our finding that fear or awareness of early signs of eye disease might stimulate smoking cessation suggests that health-promotional campaigns and health warnings providing information about the risks of smoking-related eye diseases and blindness to smokers may well be effective in eye clinic and optometry settings, as well as with the general public. Further work exploring these fears as a motivator to stop smoking among the general public in different population settings is planned. 
We have developed a leaflet targeted at smokers attending eye clinics and optometrists and propose to carry out further work investigating current practice in relation to providing smokers with advice and support in these settings (this leaflet is available at www.nwash.co.uk).

\section{References}

1 Solberg Y, Rosner M, Belkon M. The association between cigarette smoking and ocular diseases. Surv Ophthalmol 1998; 42: $535-547$.

2 Owen CG, Fletcher AE, Donoghue AR, Rudnicka AR. How big is the burden of visual loss caused by age related macular degeneration in the United Kingdom? Br J Ophthalmol 2003; 87: 312-317.
3 Kelly SP, Thornton J, Lyratzopoulos G, Edwards R, Mitchell P. Smoking and blindness. Strong evidence for the link, but public awareness lags. $\mathrm{Br}$ Med J 2004; 328: 357-358.

4 Walters N, Coleman T. Comparison of the smoking behaviour and attitudes of smokers who attribute respiratory symptoms to smoking with those who do not. Br J Gen Pract 2002; 52: 132-134.

5 Wilson N, Hodgen E, Mills J, Wilson G, Field A, Thomson G. Journal article on smoking and blindness prompts significantly more calls to Quitline. N Z Med J 2002; 115: 199-200.

6 Office for National Statistics. Neighbourhood Statistics. London: ONS, 2005. Accessed 23/02/2005. http:// neighbourhood.statistics.gov.uk/

7 Bolton Metropolitan Council. Access Bolton: People in Bolton. Bolton: Bolton Metropolitan Council, 2003. Accessed 23/02/ 2005. http://www.bolton.gov.uk/pls/portal92/docs/ 7084.HTM\#socio

8 Bryant T. Confidence Interval Analysis: Version 2.0.0. Southampton: University of Southampton, 2000. 